\title{
A Saúde Coletiva e a Criança com Comportamentos Externalizantes: uma revisão de literatura
}

\section{| ${ }^{1}$ André Guimarães, ${ }^{2}$ Luís Augusto Vasconcelos da Silva |}

Resumo: Os comportamentos externalizantes dizem de um conjunto de reaçóes impulsivas que, exteriorizadas por crianças (ou adolescentes), produzem conflitos e, em padrão repetitivo e persistente, são associados a síndromes psicopatológicas e transtornos. Este artigo tem o objetivo de revisão de literatura sobre o tema, nos três eixos disciplinares da Saúde Coletiva. Segue o método de revisão sistemática, com enfoque empírico e formato narrativo, tomando a ciência como prática social e levantando aspectos qualitativos de literatura produzida entre 2009 e 2019. Os conhecimentos produzidos trazem recortes importantes sobre o tema, porém, o panorama alcançado revela um distanciamento discursivo entre os eixos da epidemiologia e das ciências sociais em saúde, aproximados precariamente no eixo da política, planejamento e gestão em saúde. Os modos de considerar a criança nas pesquisas se dão com o silenciamento infantil, priorizando percepçóes dos adultos sobre as crianças. Chega-se a consideraçóes sobre a importância de uma efetiva interdisciplinaridade e de uma pedagogia da transdisciplinaridade capaz de transcender o lugar das especialidades e de reconhecer a criança, com a valorização das suas práticas e saberes, como ator central do conhecimento acerca de si mesma.

> Palavras-chave: saúde mental; comportamento infantil; epidemiologia, ciências sociais; política de saúde.

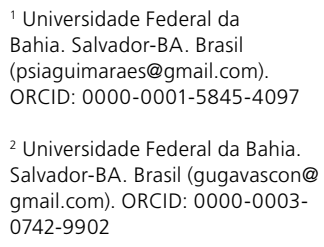

1 Universidade Federal da Bahia. Salvador-BA. Brasil (psiaguimaraes@gmail.com). ORCID: 0000-0001-5845-4097

${ }^{2}$ Universidade Federal da Bahia. Salvador-BA. Brasil (gugavascon@ gmail.com). ORCID: 0000-00030742-9902

Recebido em: 13/05/2021 Aprovado em: 03/06/2021 Revisado em: 05/10/2021 


\section{Introdução}

A Saúde Coletiva é um campo de saberes e práticas que entende a saúde como um fenômeno social e atua para o bem do interesse público em saúde, privilegiando a coletividade em relação aos indivíduos e priorizando a promoção da saúde, além da prevenção e cuidado de doenças e agravos à saúde da população (PAIM; ALMEIDA-FILHO, 2014). A produção de conhecimento na Saúde Coletiva se dá em pelo menos três eixos disciplinares: a epidemiologia; as ciências sociais em saúde e a política, planejamento e gestáo em saúde (PPGS).

À epidemiologia cabem estudos sobre o processo saúde-doença em coletividades humanas, analisando os padróes de distribuição, os fatores de risco causais e etiológicos, os efeitos sobre a saúde coletiva etc., de modo a fornecer indicadores e propostas que colaborem com o planejamento ou a avaliação de políticas, programas e tecnologias de saúde (ROUQUAYROL; ALMEIDA-FILHO, 2003). $\mathrm{O}$ eixo das ciências sociais em saúde volta-se ao levantamento de discussōes teóricas e críticas relacionadas com o universo das situaçôes e práticas sociais do processo saúde-doença-cuidado; também colaborando com o planejamento e a avaliação de políticas, programas e tecnologias de saúde (PAIM; ALMEIDA-FILHO, 2014).

Já o eixo da PPGS contempla um ramo de estudos com ênfase na política de saúde, voltado às relações Estado-sociedade e às reaçóes a condiçóes de saúde e seus determinantes, através de prioridades e propostas para a ação pública, o que inclui a relação com políticas econômicas e sociais, controle social, economia da saúde e financiamento (PAIM; TEIXEIRA, 2006). Outro ramo, com ênfase no planejamento e gestão em saúde, volta-se a estudos sobre o estabelecimento de conjuntos coordenados de açóes que visam ao alcance de objetivos sobre a saúde da população, incluindo estratégias, planejamento e avaliação de políticas, programas e tecnologias de saúde e a gestão de sistemas, serviços, recursos humanos, qualidade e financiamento (PAIM; TEIXEIRA, 2006).

A Saúde Coletiva se desenvolveu com uma proposta interdisciplinar, que pressupóe o esforço de ir além da mera justaposição de contribuiçóes específicas, estabelecendo um intercâmbio entre os seus eixos disciplinares fundamentais e, quiçá, com outras áreas de conhecimento (PAIM; ALMEIDA-FILHO, 2014). Não obstante, vários pesquisadores no campo da Saúde Coletiva vêm empreendendo diálogos com pensadores epistemológicos em busca de novos paradigmas que, para 
além de um diálogo interdisciplinar, ajudem a dar melhor conta da complexidade presente em muitos dos seus problemas de pesquisa (ALMEIDA-FILHO, 2005; ROQUETE et al, 2012). Nesse sentido, tem se discutido bastante o pensamento complexo, que se vincula à proposta de uma pedagogia da transdisciplinaridade e tem o filósofo francês Edgard Morin como um dos seus principais expoentes (ALMEIDA-FILHO, 2005; ROQUETE et al, 2012). Morin (2002) acredita que:

Para promover uma nova transdisciplinaridade precisamos de um paradigma que, certamente, permite distinguir, separar, opor e, portanto, disjuntar relativamente estes domínios científicos, mas que, também, possa fazê-los comunicarem-se entre si, sem operar a redução. O paradigma da simplificação (redução-disjunção) é insuficiente e mutilante. Torna-se necessário um paradigma de complexidade que, ao mesmo tempo disjunte e associe, que conceba os níveis de emergência da realidade sem reduzi-los às unidades elementares e às leis gerais (MORIN, 2002, p.53).

O esforço para a constituição de uma pedagogia da transdisciplinaridade, com a contribuição de diversos autores, vem elencando pressupostos que vão além da superação de fronteiras e hierarquizaçôes entre áreas do conhecimento científico, para considerar pragmaticamente as possibilidades de produção do conhecimento (D’AMBRÓSIO, 2001; MORIN, 2002; ALMEIDA-FILHO, 2005). Assim, mantendo a atenção ao método, mas com abertura aos múltiplos sistemas de explicação das realidades, se propóe considerar a incerteza e abrir mão da necessidade de ignorar, invalidar e/ou excluir os saberes populares tradicionais e de populaçóes em estudo (D’AMBRÓSIO, 2001; MORIN, 2002; ALMEIDA-FILHO, 2005).

\section{Os comportamentos externalizantes e a infância}

Os chamados comportamentos externalizantes têm aparecido com destaque entre os estudos contemporâneos sobre os problemas comportamentais na infância. Tal destaque se deve à elevada relaçáo dessa classe de comportamentos com queixas, sobretudo escolares, que têm sido associadas a síndromes psicopatológicas e a possíveis diagnósticos e terapias para crianças e adolescentes, com crescentes índices de prevalência (D’ABREU, 2012; LIMA, 2012).

Otermo comportamentos externalizantes surgiu noâmbito de estudosempregando técnicas psicométricas com o objetivo de verificar problemas comportamentais e emocionais em crianças e adolescentes em idade escolar e classificar sintomas 
psicopatológicos (ACHENBACH, 1966; ACHENBACH; ELDEBROCK, 1978). Com uma série de estudos realizada nos EUA por uma equipe multidisciplinar coordenada pelo psiquiatra Thomas Achenbach, foi desenvolvido o Achenbach System of Empirically Based Assessment (ASEBA), uma bateria de instrumentos de avaliação psicológica para múltiplos informantes, bastante utilizada atualmente em mais de cem países, incluindo o Brasil (ACHENBACH, 2017). No que tange aos problemas de comportamento em crianças e adolescentes, a bateria ASEBA é hoje composta pelos instrumentos Child Behavior Checklist (CBCL), voltado a pais/ cuidadores; Teacher's Report Form (TRF), voltado a professores - com versóes para crianças em idade pré-escolar (18 meses a 5 anos) e crianças e adolescentes em idade escolar (6 a 18 anos) e Youth Self-Report (YSR), voltado a crianças/adolescentes entre 11 e 18 anos (ACHENBACH, 2017).

A categoria comportamentos externalizantes classifica um conjunto de reaçóes impulsivas que são exteriorizadas pela criança ou adolescente de modo a proporcionar conflitos com o ambiente, tais como inquietude, desobediência, desatenção, agressividade, contestação, provocação, ruptura de regras etc. (ACHENBACH, 2017). Tais comportamentos em um padrão repetitivo e persistente são tomados como base para o diagnóstico de pelo menos três transtornos psiquiátricos chamados de transtornos externalizantes por diversos autores: o Transtorno de Déficit de Atenção e Hiperatividade (TDAH), o Transtorno Opositivo-Desafiador (TOD) e o Transtorno de Conduta (TC) (D’ABREU, 2012; LIMA, 2012).

O Manual Diagnóstico e Estatístico dos Transtornos Mentais (DSM), da Associação Americana de Psiquiatria (APA), em sua quarta edição (DSM-IV), traz os chamados transtornos externalizantes classificados como transtornos disruptivos (APA, 1997). Em sua quinta e mais recente edição (DSM-V), o TDAH teve a sua classificação alterada e passou a constar entre os transtornos do neurodesenvolvimento, juntamente com os transtornos do espectro autista, entre outros (APA, 2014). Já a décima edição da Classificação Estatística Internacional de Doenças e Problemas Relacionados à Saúde (CID-10), da Organização Mundial de Saúde (OMS), o TDAH, o TOD e o TC estão classificados entre os códigos F-90 e F-91, que correspondem, respectivamente, a transtornos hipercinéticos e transtornos de conduta (OMS; CBCD, 2008).

Esse conciso panorama histórico-conceitual dos comportamentos externalizantes demonstram sua concepção no campo psi de modo bastante imbricado com a 
categoria infância. Segundo Sarmento e Pinto (1997), a infância pode ser tomada como uma categoria social construída em processos sócio-históricos para referir um grupo de indivíduos, com distinção em relação a outros grupos, não somente pela faixa etária ou fase de desenvolvimento, mas também por uma série de significaçôes e condiçôes atribuídas que pressupóem homogeneidade e a caracterizam como um grupo minoritário, ou seja, com status social e identitário inferior.

Diversos estudos entre a Filosofia, a História, as Ciências Sociais e a Psicologia do Desenvolvimento trazem registros importantes das ideias que vêm constituindo a concepção de infância no Ocidente desde a antiguidade até a modernidade tardia (ARIÈS, 1981; DONZELOT, 1986; SARMENTO, 2018; SARMENTO; PINTO, 1997; MONTANDON, 2001; SIROTA, 2001; KOHAN, 2008; PROUT, 2010; VALENÇA, 2017). As significaçóes da infância no trânsito da história social e das ciências vêm se diversificando, desde a atribuiçâo de incapacidade e passividade à criança, chegando à identificação da criança ativa e portadora de desejos, até a mais recente significação da criança como coprodutora e constituinte da sociedade e da cultura (ARIÈS, 1981; KOHAN, 2008; PROUT, 2010; VALENÇA, 2017). No entanto, nas práticas sociais do Ocidente, entre as quais se inclui a ciência (LATOUR; WOOLGAR, 1988), a criança ainda tende a passar por atos rigorosos e naturalizados de controle e silenciamento (SARMENTO, 2005). Entende-se por silenciamento infantil o ato de ignorar, invalidar e/ou excluir a fala e o entendimento da criança, em face da inferiorização do seu status social e identitário, privilegiando o discurso do adulto, sejam pais/responsáveis, profissionais do cuidado e/ou especialistas (SARMENTO, 2005; FOUCAULT, 1996).

A presente revisão de literatura se justifica pela ausência de estudos anteriores que tenham discutido o tema conforme a proposição deste artigo. Portanto, sua importância está em problematizar, com vistas à interdisciplinaridade, à transdisciplinaridade e ao pensamento complexo, o modo como a Saúde Coletiva tem produzido conhecimento acerca de um importante tema de saúde mental referente à infância, uma categoria historicamente silenciada.

\section{Método}

Contemplando os três eixos disciplinares fundamentais da Saúde Coletiva, este trabalho se define como uma revisão sistemática qualitativa, com enfoque empírico, 
isto é, voltado a recuperar como vem se dando as pesquisas sobre um tema, sem a pretensão de determinar o "estado da arte" (BRASILEIRO, 2013). Adota-se o formato narrativo, indicado para estudos amplos de descrição e discussão de produção científica, com ênfase teórica ou contextual, a partir do levantamento de aspectos qualitativos estabelecidos pelo autor (ROTHER, 2007).

Logo, o estudo é orientado pelas seguintes questôes: Como tem se desenvolvido, no campo da Saúde Coletiva, a produção de conhecimento acerca da problemática da criança com comportamentos externalizantes? Com os três eixos disciplinares da Saúde Coletiva, como têm se dado o diálogo interdisciplinar e os modos de considerar a criança nas pesquisas sobre problemas de comportamento e saúde mental infantil? A escolha por abranger os três eixos da Saúde Coletiva se deve ao zelo pela interdisciplinaridade, tomando a ciência como prática social que, na mediação com pesquisadores, sujeitos/objetos e referenciais de estudo, em diversas realidades, produz saberes entre os quais se espera diálogo (LATOUR, WOOLGAR, 1988).

As buscas por referências foram realizadas de modo sistemático nas bases do Portal de Periódicos CAPES/MEC (Google Acadêmico; PsycINFO), em 12 de janeiro de 2020, a partir dos seguintes parâmetros: a) Período de Publicação: de 2009 a 2019; b) Tipo de Material: artigos; c) Idioma: qualquer; d) Descritores: "mental health"; "child"; "problem behavior"; "disorders"; "public health"-pesquisados conjuntamente. Com vistas ao refinamento, acionando o botão 'AND', foram acrescentados para cruzamento referente a cada eixo disciplinar, respectivamente, os descritores "epidemiology"; ou "social sciences"; ou "health policy".

Os critérios de inclusão foram: estudos nacionais ou internacionais incluindo o Brasil; sobre comportamento(s) externalizante(s); e/ou sobre transtorno(s) externalizante(s); e/ou sobre estratégia(s), programa(s) e/ou serviço(s) público(s) que atendem a crianças (de até 12 anos) a quem se atribui a referida condição de saúde mental. Excluíram-se publicaçóes que: a) se definiam como estudos de revisão; cartas ao editor ou anais de eventos; b) não se referiam ao território brasileiro; c) o periódico não constava na classificação Qualis/CAPES (2013-2016) da área de Saúde Coletiva; d) não foram localizados na íntegra. Os critérios de relevância para a escolha dos artigos descritos e discutidos nesta revisão, como representativos da amostra, entre si, foram a variedade de foco, metodologia, resultados e âmbito/local do estudo.

Nos resultados das buscas foram listadas para o eixo da epidemiologia 471 publicaçóes, das quais foram selecionadas 175 pela leitura do título e/ou resumo, 31 
pelos critérios de inclusão, chegando à amostra final de 9 pelos critérios de exclusão. Para o eixo das ciências sociais em saúde listaram-se 301 publicaçóes, das quais foram selecionadas 103 pela leitura do título e/ou resumo, 27 pelos critérios de inclusão e 7 pelos critérios de exclusão. Para o eixo da PPGS, de 298 publicaçóes listadas, 96 foram selecionadas pela leitura do título e/ou resumo, 29 pelos critérios de inclusão e 6 pelos critérios de exclusão.

Da amostra final, 5 artigos de cada eixo disciplinar foram escolhidos para a análise pelos critérios de relevância, com atenção à forma e conteúdo, de modo a constituir um panorama empírico das pesquisas sobre o tema no campo da Saúde Coletiva. Na discussão, adota-se a linguagem da complexidade, da multiplicidade e das mediaçóes do mundo social, no qual a ciência se insere como prática (LATOUR; WOOGAR, 1988; PROUT, 2010; LATOUR, 2012).

\section{Resultados e discussão}

\section{Literatura em Epidemiologia}

No tocante à criança com comportamentos externalizantes, a epidemiologia tem realizado estudos descritivos diversos, que têm por objetivo caracterizar a distribuição do problema ou condiçóes relacionadas, de modo a responder onde, quando, com o quê e quem o problema alcança (ROUQUAYROL; ALMEIDA-FILHO, 2003). Assim, a epidemiologia descritiva busca traçar as variações da incidência (casos novos) ou da prevalência (casos existentes) de uma dada condição de saúde de acordo com certas características, sejam sociodemográficas, familiares, habituais etc., que possam representar fatores de risco (ROUQUAYROL; ALMEIDA-FILHO, 2003). Nesta revisão foram selecionados, da epidemiologia descritiva, um estudo nacional do tipo ecológico, dois nacionais do tipo transversal de prevalência e dois do tipo longitudinal prospectivo, ou de coorte, sendo um internacional e outro nacional, conforme expostos em resumo no Quadro 1. 
Quadro 1. Resumo dos estudos da epidemiologia acerca da criança com comportamentos externalizantes.

\begin{tabular}{|c|c|c|}
\hline Estudo & Metodologia & Resultados/Considerações \\
\hline $\begin{array}{l}\text { I. Centros de } \\
\text { Atenção Psicossocial } \\
\text { Infantojuvenil no } \\
\text { Brasil: distribuição } \\
\text { geográfica e perfil } \\
\text { dos usuários } \\
\text { (GARCIA; } \\
\text { SANTOS; } \\
\text { MACHADO, } \\
\text { 2015). }\end{array}$ & $\begin{array}{l}\text { Tipo: Ecológico de múltiplos grupos } \\
\text { (quantit.) - busca apresentar um panorama } \\
\text { descritivo de diferenças entre populaçóes } \\
\text { estudadas com base em dados secundários, } \\
\text { comparando a frequência e distribuição de } \\
\text { problemas entre diferentes grupos em um } \\
\text { dado período. } \\
\text { Âmbito/Local: Nacional, Brasil. } \\
\text { Sujeitos/Objeto: Crianças e adolescentes } \\
\text { de ambos os sexos com demandas de saúde } \\
\text { mental, atendidos em Centro de Atenção } \\
\text { Psicossocial - Infância e adolescência } \\
\text { (CAPSi), estes pesquisados sobre distribuiçáo } \\
\text { nacional e perfil nosológico de atendimentos. } \\
\text { Técnicas/Instrumentos: Consulta a dados } \\
\text { de dois sistemas nacionais de informação } \\
\text { de saúde: Autorizaçóes de Pagamento de } \\
\text { Serviços de Alta Complexidade (APAC) e } \\
\text { Cadastro Nacional de Estabelecimentos de } \\
\text { Saúde (CNES). }\end{array}$ & $\begin{array}{l}\text { De } 2008 \text { a 2012, a maior parte } \\
\text { dos atendimentos nos CAPSi } \\
(29,7 \%) \text { foram para transtornos } \\
\text { relacionados a problemas de } \\
\text { comportamento; por faixa etária, } \\
\text { esses transtornos representaram } \\
39 \% \text { entre os usuários de } 5 \text { a } \\
9 \text { anos e } 32 \% \text { entre os de } 10 \text { a } \\
14 \text { anos. No mesmo período, } \\
68,8 \% \text { dos atendimentos gerais } \\
\text { dos CAPSi foram para crianças e } \\
\text { adolescentes do sexo masculino. } \\
\text { Sinaliza a importância da } \\
\text { integraçáo da rede especializada } \\
\text { com a atençáo básica e da } \\
\text { articulaçáo intersetorial no } \\
\text { território/comunidade. }\end{array}$ \\
\hline $\begin{array}{l}\text { II. Prevalence of } \\
\text { Behavior Problems } \\
\text { and Associated } \\
\text { Factors in Preschool } \\
\text { Children from the } \\
\text { City of Salvador, } \\
\text { State of Bahia, } \\
\text { Brazil (SANTOS et } \\
\text { al, 2016). }\end{array}$ & $\begin{array}{l}\text { Tipo: Transversal de prevalência (quantit.) - } \\
\text { observa e descreve a relação fator-efeito para } \\
\text { casos existentes de dada condição de saúde } \\
\text { em um grupo populacional e em um recorte } \\
\text { de tempo específico. } \\
\text { Âmbito/Local: Nacional, município de } \\
\text { Salvador, estado da Bahia. } \\
\text { Sujeitos/Objeto: Crianças em idade pré- } \\
\text { escolar pesquisadas sobre a prevalência de } \\
\text { problemas de comportamento e fatores } \\
\text { associados. } \\
\text { Técnicas/Instrumentos: Aplicação de } \\
\text { questionário sociodemográfico e do } \\
\text { instrumento CBCL da bateria ASEBA (pais/ } \\
\text { cuidadores) para medir a frequência de } \\
\text { problemas de comportamento nas crianças }\end{array}$ & $\begin{array}{l}\text { Indica-se a prevalência global } \\
\text { de } 23,5 \% \text { para problemas } \\
\text { comportamentais; prevalência } \\
\text { de } 25,2 \% \text { para comportamentos } \\
\text { externalizantes e de } 9,7 \% \text { para } \\
\text { comportamentos internalizantes. } \\
\text { A saúde mental materna é } \\
\text { apresentada como um importante } \\
\text { fator de risco para problemas } \\
\text { comportamentais nas crianças, } \\
\text { com destaque para as seguintes } \\
\text { variáveis: transtorno de ansiedade, } \\
\text { transtorno afetivo e transtornos } \\
\text { relacionados ao uso de substâncias } \\
\text { psicoativas. Observa que a saúde } \\
\text { mental materna é um importante } \\
\text { fator de risco para problemas de } \\
\text { comportamento em crianças em } \\
\text { idade pré-escolar. }\end{array}$ \\
\hline
\end{tabular}




\begin{tabular}{|c|c|}
\hline Estudo & Metodologia \\
\hline \multirow{14}{*}{$\begin{array}{l}\text { III. Desigualdades } \\
\text { Socioeconômicas } \\
\text { e Saúde Mental } \\
\text { Infantil (ASSIS, } \\
\text { AVANCI, } \\
\text { OLIVEIRA, 2009). }\end{array}$} & Tipo: Transversal de prevalência (quantitat.) \\
\hline & - idem do anterior. \\
\hline & Âmbito/Local: Nacional, município de São \\
\hline & Gonçalo, estado do Rio de Janeiro. \\
\hline & Sujeitos/objeto: Crianças estudantes da \\
\hline & primeira série do ensino fundamental na \\
\hline & rede pública de educaçáo pesquisadas sobre a \\
\hline & relação entre problemas de comportamento e \\
\hline & desigualdades socioeconômicas. \\
\hline & Técnicas/Instrumentos: Aplicação de \\
\hline & questionário sociodemográfico e do \\
\hline & instrumento CBCL da bateria ASEBA (pais/ \\
\hline & cuidadores) para medir a frequência de \\
\hline & problemas de comportamento nas crianças. \\
\hline
\end{tabular}

Resultados/Consideraçóes

Crianças cujas famílias são monoparentais ou com a presença de padrasto/madrasta, com baixa escolaridade dos pais, em situação de extrema pobreza e com a cor de pele preta apresentaram mais problemas de comportamento e frágil competência social. Quanto mais desses fatores de risco estão presentes, mais cresce a prevalência das crianças com problemas de comportamento e competência social. Aponta a importância de políticas públicas e ações de prevenção e assistência.

IV. Amamentação e comportamentos externalizantes na infância e adolescência em uma coorte de nascimentos (POTON et al, 2017).
Tipo: Longitudinal prospectivo ou de coorte (quantit.) - acompanha um grupo populacional durante um longo período e descreve a relação entre a exposição a fator(es) e seu(s) efeito(s).

Âmbito/Local: Nacional, município de Pelotas, estado do Rio Grande do Sul.

Sujeitos/Objeto: Sujeitos em desenvolvimento, pesquisados sobre a relaçáo entre tempo de amamentação e ocorrência de comportamentos externalizantes na infância e adolescência.

Técnicas/Instrumentos: Levantamento de dados da Coorte de Nascimentos de Pelotas (1993) com informaçôes sociofamiliares no perinatal e no desenvolvimento dos sujeitos. Aplicação dos instrumentos para pais/ cuidadores CBCL/ASEBA, aos 4 anos, e Strengths and Difficulties Questionnaire (SDQ), aos 11 e 15 anos, para medir a frequência de problemas de comportamento.
As crianças que foram amamentadas por pelo menos 6 meses tiveram menor risco de hiperatividade aos 11 anos em comparação às amamentadas por menos de 1 mês. Porém, aos 4 e 15 anos, os comportamentos externalizantes avaliados não apareceram associados ao tempo de amamentação. Recomenda novos estudos longitudinais considerando outros fatores que possam influenciar sobre comportamentos externalizantes, como presença do pai no ambiente familiar, violência doméstica, qualidade da relação mãe-filho e maus-tratos. 


\begin{tabular}{|c|c|c|}
\hline Estudo & Metodologia & Resultados/Consideraçóes \\
\hline $\begin{array}{l}\text { V. Childhood } \\
\text { behaviour problems } \\
\text { predict crime } \\
\text { and violence in } \\
\text { late adolescence: } \\
\text { Brazilian and British } \\
\text { birth cohort studies } \\
\text { (MURRAY et al, } \\
\text { 2015). }\end{array}$ & $\begin{array}{l}\text { Tipo: Longitudinal prospectivo ou de coorte } \\
\text { (quantit.) - idem do anterior. } \\
\text { Âmbito/Local: Internacional - Brasil e } \\
\text { Inglaterra. } \\
\text { Sujeitos/Objeto: Sujeitos em desenvolvimento } \\
\text { pesquisados sobre a relaçáo entre fatores } \\
\text { ambientais, problemas de comportamento na } \\
\text { infância e criminalidade na juventude. } \\
\text { Técnicas/Instrumentos: Comparaçáo } \\
\text { dedados entre os estudos de coorte de } \\
\text { nascimentos de Pelotas-RS, Brasil (1993) } \\
\text { e de Avon, Inglaterra (1991), considerando } \\
\text { fatores sociofamiliares no perinatal e no } \\
\text { desenvolvimento dos sujeitos, incluindo } \\
\text { crimes parentais. Aplicaçáo do instrumento } \\
\text { SDQ (pais/cuidadores) para medir a } \\
\text { frequência de problemas de comportamento, } \\
\text { aos } 11 \text { anos. Realizaçáo de entrevista de } \\
\text { autorrelato, com vistas a crimes, aos } 18 \text { anos. }\end{array}$ & $\begin{array}{l}\text { A relação de problemas } \\
\text { comportamentais na infância } \\
\text { com crimes violentos na } \\
\text { juventude foi mais prevalente } \\
\text { no Brasil e, com crimes não- } \\
\text { violentos, foram mais prevalentes } \\
\text { na Inglaterra. As taxas de } \\
\text { prevalência foram maiores para } \\
\text { o sexo masculino. Problemas de } \\
\text { comportamento e hiperatividade } \\
\text { previram crimes náo-violentos } \\
\text { e violentos de modo semelhante } \\
\text { nos dois países, com efeitos } \\
\text { parcialmente explicados por } \\
\text { fatores ambientais e de saúde } \\
\text { perinatal. Sugere programas } \\
\text { de prevenção à criminalidade } \\
\text { e violência com alvo nos } \\
\text { comportamentos infantis e riscos } \\
\text { associados, tanto em países de } \\
\text { baixa renda como de alta renda. }\end{array}$ \\
\hline
\end{tabular}

Os estudos epidemiológicos descritivos acerca da criança com comportamentos externalizantes têm produzido conhecimentos importantes, com recortes expressivos dessa complexa problemática. No entanto, tais conhecimentos podem ser tomados e atuados de diferentes formas, a depender dos pressupostos teóricos ou de ação, ou das abordagens aos quais passam a ser associados, podendo gerar influências diversas na formulação de políticas públicas em saúde mental para a infância. Tratase de informaçóes quantitativas, com viés de generalidade, que ao serem associadas, por exemplo, a pressupostos biomédicos podem ser atuadas de modo a corroborar teorias neuropsiquiátricas individualizantes que embasam psicodiagnósticos e abordagens terapêuticas farmacológicas, ou, nomeadamente, as práticas de medicalização e medicamentalização do comportamento infantil (CONRAD, 2007; NGOUNDO-MBONGUE et al, 2005; SIQUEIRA; GURGEL-GIANERTTI, 2011; VINOCUR; PEREIRA, 2011). Entende-se por medicalização o processo que fixa como problemas patológicos e individuais as condiçóes que expressam desvio da normalidade e/ou experiências de sofrimento social ou intersubjetivo, impondo 
classificaçóes e tratamentos concebidos em linguagem biomédica (CONRAD, 2007). Já o termo medicamentalização diz do processo que envolve a produção de medicamentos e a demanda por terapias farmacológicas como recurso único ou prioritário para prevenção ou tratamento de problemas que foram medicalizados (NGOUNDO-MBONGUE et al, 2005).

As mesmas informaçóes da epidemiologia, ao serem associadas a abordagens críticas das ciências sociais e humanas, podem ser atuadas de modo a propor a compreensão qualitativa de determinantes socioambientais, com a problematização dos processos psicodiagnósticos, ou opondo-se diretamente ao enfoque biomédico e aos atos medicalizantes (BRZOZOWSKI, CAPONI, 2012; STOLKINER, 2012). Vale ainda acrescentar que, no campo da Psicologia, as informaçóes epidemiológicas referentes à criança com comportamentos externalizantes tendem a mediar direta ou indiretamente principalmente duas linhas de produção de conhecimento. Uma, nos trabalhos da Análise do Comportamento e da Terapia Cognitivo-Comportamental (TCC), em diálogo com teorias psicopatológicas e psicoterápicas, atuam de modo a produzir ou corroborar métodos de abordagens clínicas e de treinamento infantil, parental/familiar e de profissionais que atuam com as crianças (BARROS; SILVA, 2006; CALEIRO; SILVA, 2012). Outra linha, nos trabalhos da Psicologia Escolar e Educacional, em diálogo com as abordagens críticas das ciências sociais e humanas e com a Psicologia do Desenvolvimento, atua de modo a problematizar os processos de escolarização, a queixa escolar e as práticas de medicalização associadas, também propondo novas formas de atuação profissional nos contextos intersetoriais da comunidade escolar (SOUZA, 2007; ANGELUCCI; SOUZA, 2010).

Em suas consideraçóes, os estudos da epidemiologia descritiva sobre os problemas de comportamento na infância têm enfatizado desde a afirmação de fatores de risco até a necessidade de novos estudos ou a recomendação de açóes e de políticas públicas pontuais ou intersetoriais. Entretanto, em se tratando de estudos produzidos no contexto paradigmático da Saúde Coletiva, faz falta que haja ao menos uma sinalização para o diálogo interdisciplinar com estudos das ciências sociais em saúde que problematizem qualitativamente os determinantes sociais verificados para os comportamentos externalizantes na infância e as suas circunstâncias mais profundas. Isso porque, é de certo arriscado permitir que, por exemplo, a cor da pele preta da criança, ou a pobreza, ou o modelo familiar, 
ou a baixa escolaridade dos pais sejam simplificados como fatores de risco para problemas de comportamento. Com isso, seria importante considerar a provável vulnerabilidade da criança a alguns tipos de violência intersubjetiva relacionadas, como racismo e discriminação identitária, cultural e de classe.

Se os estudos epidemiológicos descritivos são realizados com ênfase ou a partir do contexto escolar, pelos riscos de restrição ou individualização do problema, é importante sinalizar a necessidade de diálogo com estudos que discutem os modelos escolares, considerando o processo de escolarização e as práticas cotidianas na comunidade escolar. Considerar o "processo de escolarização" significa enfatizar a escola como "o espaço em que relaçóes sociais e individuais se articulam em uma rede de relações complexas" (ANGELUCCI; SOUZA, 2010, p.60). Assim, os problemas que emergem no contexto escolar podem ser analisados como efeitos de questôes relacionais mais profundas que, provavelmente, não se limitam aos muros da escola (ANGELUCCI; SOUZA, 2010). A falta de tais sinalizaçóes para o diálogo interdisciplinar pode aparentar, por implícito, um viés biomédico.

Os modos de considerar a criança nas pesquisas da epidemiologia descritiva, tomando por base a representação dos estudos nesta revisão, apresentam em graus diferenciados o componente de silenciamento infantil. Silenciamento este que, em geral, se dá associado à priorização das percepçôes do adulto sobre os comportamentos da criança e/ou ao uso exclusivo de instrumentos de avaliação psicológica que aferem construtos teóricos elaborados por "especialistas", com viés biomédico, na lógica do checklist e de modo distanciado de fatores circunstanciais. Nos estudos transversais de prevalência e nos longitudinais prospectivos é privilegiado o uso de instrumentos de avaliação das crianças dirigido para os pais/cuidadores, sendo que a criança não é avaliada diretamente. Apenas o estudo V (MURRAY et al, 2015) indica a aplicação direta de um instrumento de produção de dados para os atores centrais do estudo, que foram avaliados desde o nascimento, porém, a entrevista de autorrelato somente foi utilizada quando aqueles sujeitos já haviam completado 18 anos.

\section{Literatura em Ciências Sociais em Saúde}

Os estudos relativos à problemática da criança com comportamentos externalizantes, inscritos no eixo das ciências sociais em saúde, apresentam metodologias qualitativas diversas e, em geral, são pouco voltados aos processos de constituiçấo dos comportamentos infantis considerados problemáticos em si. 
O foco principal desses estudos têm sido a problematização da psicopatologia da infância com críticas aos processos psicodiagnósticos e às práticas de medicalização e medicamentalização do comportamento infantil. Nesse sentido, se opóem direta ou indiretamente ao discurso biomédico, não se referindo à categoria comportamentos externalizantes e raramente utilizando o termo transtornos externalizantes. Para tratar dos processos de medicalização e medicamentalização dos problemas de comportamento infantil, é tomado especialmente como mote o diagnóstico do TDAH, devido à sua popularização e prevalência crescentes nas últimas décadas. Dos estudos qualitativos das ciências sociais em saúde foram selecionados dois internacionais de revisão sócio-histórica e três nacionais, sendo um documental, um de práticas discursivas e produção de sentidos e um de inspiração etnográfica, conforme descritos em resumo no próximo Quadro 2.

Quadro 2. Resumo dos estudos das ciências sociais em saúde acerca da criança com comportamentos externalizantes.

\begin{tabular}{|c|c|c|}
\hline Estudo & Metodologia & Resultados/Consideraçóes \\
\hline $\begin{array}{l}\text { VI. The Impending } \\
\text { Globalization of } \\
\text { ADHD: notes on the } \\
\text { expansion and growth } \\
\text { of a medicalized } \\
\text { disorder (CONRAD; } \\
\text { BERGEY, 2014). }\end{array}$ & $\begin{array}{l}\text { Tipo: Revisão sócio-histórica (qualitat.) } \\
\text { - busca recuperar os processos de } \\
\text { construção social de um tema, categoria } \\
\text { conceitual, fenômeno ou acontecimento } \\
\text { no curso da história, possibilitando a } \\
\text { apresentação e discussão de panoramas } \\
\text { qualitativos. } \\
\text { Âmbito/Local: Internacional, com } \\
\text { ênfase nos EUA, Reino Unido, } \\
\text { Alemanha, França, Itália e Brasil. } \\
\text { Sujeitos/Objeto: O TDAH, pesquisado } \\
\text { acerca da expansão do seu diagnóstico } \\
\text { e tratamento (medicalização) para o } \\
\text { contexto global a partir dos EUA. } \\
\text { Técnicas/Instrumentos: Análise } \\
\text { documental referente a dados oficiais e } \\
\text { sítios da internet e revisão de literatura } \\
\text { com ênfase histórica. }\end{array}$ & $\begin{array}{l}\text { A expansão da medicalização do } \\
\text { déficit de atenção e hiperatividade } \\
\text { para o Reino Unido, Alemanha, } \\
\text { França, Itália e Brasil se deu com } \\
\text { algumas diferenças, porém, com } \\
\text { a influência fundamental da } \\
\text { psiquiatria ocidental representada } \\
\text { no DSM e no CID, das indústrias } \\
\text { farmacêuticas multinacionais e da } \\
\text { internet, que disponibiliza testes } \\
\text { de verificação de diagnóstico, bem } \\
\text { como páginas de grupos de apoio } \\
\text { e associações de "portadores de } \\
\text { TDAH" e pais/cuidadores, que } \\
\text { atuam gerando bioidentidades e } \\
\text { compartilhamento de soluçôes. } \\
\text { Indica que a globalização do TDAH } \\
\text { pode potencializar a medicalização } \\
\text { de outras condiçóes de saúde mental. }\end{array}$ \\
\hline
\end{tabular}

continua... 


\begin{tabular}{|c|c|c|}
\hline Estudo & Metodologia & Resultados/Consideraçóes \\
\hline $\begin{array}{l}\text { VII. As Controvérsias } \\
\text { Sócio-Históricas } \\
\text { das Práticas } \\
\text { Farmacológicas com } \\
\text { o Metilfenidato } \\
\text { (DOMITROVIC; } \\
\text { CALIMAN, 2017). }\end{array}$ & $\begin{array}{l}\text { Tipo: Revisão sócio-histórica } \\
\text { (qualitativo) - idem do anterior. } \\
\text { Âmbito/Local: Internacional, com } \\
\text { ênfase nos EUA e Brasil. } \\
\text { Sujeitos/Objeto: O metilfenidato } \\
\text { pesquisado acerca das práticas e } \\
\text { sentidos produzidos no meio científico } \\
\text { em torno da sua importância e crescente } \\
\text { utilizaçáo como psicoestimulante no } \\
\text { tratamento do TDAH. } \\
\text { Técnicas/Instrumentos: Análise de } \\
\text { discurso, de referencial foucaultiano, } \\
\text { da literatura científica acerca do } \\
\text { metilfenidato, desde a sua emergência } \\
\text { histórica como problema sociotécnico. }\end{array}$ & $\begin{array}{l}\text { O alto consumo do metilfenidato } \\
\text { ancora-se à ampliação do } \\
\text { diagnóstico do TDAH, defendida } \\
\text { como avanço técnico frente à tese } \\
\text { de elevado índice de sintomáticos e, } \\
\text { rechaçada sob a tese de banalização } \\
\text { do diagnóstico medicalizante em } \\
\text { detrimento da atençáo a questôes } \\
\text { socioculturais inerentes ao TDAH. } \\
\text { Os discursos científicos acerca do } \\
\text { metilfenidato refletem em debates } \\
\text { políticos e sociais, expressando } \\
\text { como dados controversos podem } \\
\text { ser tomados enquanto "problemas". } \\
\text { Enfatiza a necessidade de sustentar } \\
\text { discussóes críticas com vistas ao } \\
\text { progresso das políticas públicas } \\
\text { em saúde mental para a infância e } \\
\text { adolescência. }\end{array}$ \\
\hline $\begin{array}{l}\text { VIII. Estudo } \\
\text { sobre o Processo } \\
\text { de Medicalização } \\
\text { de Crianças no } \\
\text { Campo da Saúde } \\
\text { Mental (SANCHES; } \\
\text { AMARANTE, 2014). }\end{array}$ & $\begin{array}{l}\text { Tipo: Documental (qualitativo) } \\
\text { - busca compreender as práticas } \\
\text { relativas a determinado fenômeno ou } \\
\text { objeto a partir de registros feitos em } \\
\text { documentos. } \\
\text { Âmbito/Local: Nacional, município } \\
\text { do Rio de Janeiro, estado do Rio de } \\
\text { Janeiro. } \\
\text { Sujeitos/objeto: Crianças atendidas no } \\
\text { serviço de saúde mental do Centro de } \\
\text { Saúde da Escola Nacional de Saúde } \\
\text { Pública da Fundaçáo Oswaldo Cruz, } \\
\text { estudadas sobre como suas práticas no } \\
\text { dia-dia passam a ser entendidas como } \\
\text { problemas médicos. } \\
\text { Técnicas/Instrumentos: Análise do } \\
\text { discurso foucaultiana de prontuários de } \\
\text { atendimento. }\end{array}$ & $\begin{array}{l}\text { É confirmada a hipótese de que } \\
\text { o discurso biomédico e processos } \\
\text { de medicalização tomam parte } \\
\text { do cotidiano da vida das crianças } \\
\text { brasileiras, de modo a se tratar como } \\
\text { doenças questóes comportamentais } \\
\text { e/ou relacionais inerentes ao seu } \\
\text { desenvolvimento. A queixa escolar } \\
\text { figurou como principal fator de } \\
\text { encaminhamento das crianças para } \\
\text { o serviço de saúde. Evoca o potencial } \\
\text { positivo da busca por soluçôes } \\
\text { comprometidas com o amplo } \\
\text { diálogo no cotidiano das relaçóes } \\
\text { comunitárias, em vez de se delegar } \\
\text { a administraçấo de determinados } \\
\text { problemas a "especialistas". }\end{array}$ \\
\hline
\end{tabular}




\begin{tabular}{|c|c|c|}
\hline Estudo & Metodologia & Resultados/Consideraçóes \\
\hline $\begin{array}{l}\text { IX. Sentidos } \\
\text { Construídos por } \\
\text { Educadores sobre } \\
\text { Transtorno do } \\
\text { Déficit de Atenção } \\
\text { e Hiperatividade e } \\
\text { Implicações para a } \\
\text { Prática Educativa } \\
\text { (LORENZI; } \\
\text { RISSATO; SILVA, } \\
\text { 2012). }\end{array}$ & $\begin{array}{l}\text { Âmbito/Local: Nacional, município de } \\
\text { pequeno porte no estado de Sáo Paulo. } \\
\text { Sujeitos/Objeto: Professores do Ensino } \\
\text { Fundamental I, pesquisados sobre os } \\
\text { sentidos produzidos acerca de sintomas } \\
\text { e diagnóstico de TDAH em crianças } \\
\text { estudantes. }\end{array}$ & $\begin{array}{l}\text { Os sentidos produzidos pelas } \\
\text { professoras transitam entre a } \\
\text { culpabilizaçáo dos pais/cuidadores } \\
\text { pelos comportamentos das crianças } \\
\text { e a adesão ao discurso biomédico na } \\
\text { medicalizaçáo do comportamento } \\
\text { infantil. Aponta fragilidade na } \\
\text { segurança das professoras em lidar } \\
\text { com a questão do TDAH, o que } \\
\text { atrapalha as práticas educativas. } \\
\text { Defende a importância de se } \\
\text { construir espaços de diálogo entre } \\
\text { professores para a reflexáo crítica } \\
\text { sobre o tema, de modo a transformar } \\
\text { práticas educativas e diminuir a } \\
\text { adesão ao discurso e às soluçóes } \\
\text { biomédicas. }\end{array}$ \\
\hline $\begin{array}{l}\text { X. Comportamentos } \\
\text { infantis } \\
\text { problemáticos, } \\
\text { perturbadores e náo } \\
\text { conformes: Conceitos } \\
\text { e demandas de } \\
\text { cuidado relacionados } \\
\text { à agitação em } \\
\text { crianças em Santos } \\
\text { e Campinas, Brasil } \\
\text { (NAKAMURA; } \\
\text { BARBARINI, 2019). }\end{array}$ & $\begin{array}{l}\text { Tipo: De inspiração etnográfica } \\
\text { (qualitat.) - busca o contato direto } \\
\text { com realidades vividas no cotidiano } \\
\text { dos sujeitos/objetos de estudo, os } \\
\text { discursos circulantes e as instituiçôes } \\
\text { relacionadas. } \\
\text { Âmbito/Local: Nacional, municípios } \\
\text { de Santos e Campinas, estado de Sáo } \\
\text { Paulo. } \\
\text { Sujeitos/Objeto: Crianças de } 3 \\
\text { a } 12 \text { anos, com problemas de } \\
\text { comportamento, atendidas em três } \\
\text { Serviços de Saúde Mental Infantil } \\
\text { (SSMI), pesquisadas sobre os conceitos } \\
\text { e demandas de cuidado relacionados às } \\
\text { síndromes psicopatológicas atribuídas. } \\
\text { Técnicas/Instrumentos: Análise } \\
\text { documental de prontuários de } \\
\text { atendimento, observaçáo participante } \\
\text { e análise de discurso a partir de } \\
\text { entrevistas semiestruturadas individuais } \\
\text { com profissionais de saúde, familiares } \\
\text { e crianças. }\end{array}$ & $\begin{array}{l}\text { Entendida como categoria } \\
\text { multidimensional e vaga, associada } \\
\text { a classes diagnósticas, como o } \\
\text { TDAH, a "agitação" foi tomada } \\
\text { como questão central em casos } \\
\text { encaminhados aos SSMI. Observa- } \\
\text { se cruzamento entre conceitos } \\
\text { científicos e do senso comum } \\
\text { de agitação, que implicam a } \\
\text { banalização do diagnóstico e o } \\
\text { estigma de disfunçáo biopisicológica } \\
\text { do comportamento infantil, a } \\
\text { partir de modelos adultos. Conclui- } \\
\text { se destacando a necessidade de } \\
\text { aprofundar estudos que privilegiem } \\
\text { a visão das crianças sobre suas } \\
\text { relaçốes com os adultos, valorizando } \\
\text { seus posicionamentos e sua formação } \\
\text { identitária. }\end{array}$ \\
\hline
\end{tabular}


Os estudos das ciências sociais em saúde acerca da criança com comportamentos externalizantes também têm produzido uma gama de conhecimentos bastante importantes, com os seus recortes dessa problemática. Tais conhecimentos tendem à aproximação discursiva com as áreas críticas ou socialmente sensíveis da Psicologia e da Educação. A representação dos estudos sociais analisados é expressiva na polarização das chamadas ciências leves (ou sociais e humanas), de viés qualitativo, com as "ciências duras" (ou naturais), de viés biológico e quantitativo. O panorama apresentado fica marcado por uma fraca disposição ou dificuldade para o diálogo interdisciplinar, especialmente com as ciências médicas e farmacêuticas.

Ainda que os dados epidemiológicos, as teorias neuropsiquiátricas e os produtos psicofarmacológicos apareçam nos estudos, muitas vezes de modo transversal, em geral, são situados com oposição discursiva e tratados em termos de práticas hegemônicas, dispositivos de controle, biopolítica, biopoder, medicalização, medicamentalização etc. Não obstante, em se tratando de uma polarização tão marcada, éimportante atentar para os riscos da "sociologização" ou "antropologizaçâo" (KLEINMAN; KLEINMAN, 1991) do tema - além dos riscos de "psicologização" ou "pedagogização", bastante semelhantes à "biologização", comumente apontada nas ciências duras. Ou seja, é preciso estar sempre vigilante para a inconveniente ancoragem de temas relativos aos processos de saúde-doença-cuidado como problema prioritário ou de domínio exclusivo de certa disciplina ou "especialidade", o que é passível de ocorrer nas diversas áreas de conhecimento.

As consideraçóes trazidas nos estudos das ciências sociais em saúde sugerem reflexividade e enfatizam a crítica negativa ao poder da medicina e da indústria farmacêutica e às suas relaçóes com instituiçóes como o Estado, o mercado, a escola e a família. Esse discurso crítico opositor pode recair na controversa tendência a hierarquizaçôes e a duras generalidades, que comprometem o diálogo interdisciplinar caro à Saúde Coletiva, com prejuízo para o alcance do pensamento complexo e para açóes políticas mais acertadas. Toda a polarização presente nas ciências sociais e humanas em relação ao biomédico e às ciências naturais, em geral, também pode estar comprometendo a produção de estudos sociais que explorem a complexidade das redes em que é constituído o comportamento infantil tomado como problemático.

Há de se reconhecer a importância histórica do discurso opositor das ciências sociais e humanas, politicamente necessário para fragilizar a hegemonia do discurso biomédico na saúde mental, que vem produzindo diversos problemas referentes 
aos processos de cuidado (SANCHES; AMARANTE, 2014; DOMITROVIC; CALIMAN, 2017; LORENZI; RISSATO; SILVA, 2012; NAKAMURA; BARBARINI, 2019). No entanto, diferentemente do passado, as controvérsias da psicopatologia, dos critérios psicodiagnósticos e da terapêutica psiquiátrica, com os seus efeitos iatrogênicos, não são mais abordadas criticamente apenas por sociólogos, antropólogos e filósofos. Com o tempo, as abordagens interdisciplinares ampliaram a discussão para outros campos, como a Psicologia e a Educação. Hoje, seja de modo geral ou especialmente em relação aos problemas de comportamento infantil, os "abusos" da psiquiatria são razoavelmente discutidos no próprio campo da medicina em estudos críticos de psiquiatras influentes, como Frances (2016) e Landman (2015), no âmbito internacional, e como Amarante (2017) e Lima (2012), no âmbito nacional. Então, não seria tempo de as ciências sociais e humanas em saúde passarem a consolidar a produção de estudos com enfoque nos fenômenos relativos às práticas humanas que se dão no contexto das redes, com a complexidade e a heterogeneidade das relaçóes, quebrando dicotomias e deixando em suspenso as teorias e as práticas hegemônicas e contra-hegemônicas na saúde mental? No que tange aos problemas do comportamento infantil, há carência de estudos com essa proposição.

Os modos de considerar a criança nas pesquisas das ciências sociais em saúde, tendo por referência a representação dos estudos nesta revisão, também apresentam de modo geral, modulaçóes de silenciamento infantil. As pesquisas sociais em saúde também têm apresentado metodologias que priorizam a percepção dos adultos, sejam pais, professores ou "especialistas", sobre as crianças. Ainda são poucos os estudos nas ciências sociais em saúde que utilizam observação e entrevista com a criança sobre si mesma, de modo a considerar e destacar a sua atuação em seus ambientes de desenvolvimento, com os sentidos e a cultura que produz. Nesta revisão, uma proposta menos hierarquizante de pesquisa em relação aos saberes da infância aparece apenas no estudo X (NAKAMURA; BARBARINI, 2019), no qual as crianças foram abordadas diretamente em apenas um dos locais de pesquisa.

\section{Literatura em Política, Planejamento e Gestão em Saúde}

Nesta parte da revisão de literatura, com o eixo da PPGS, não foram encontrados estudos internacionais, incluindo o Brasil. $\mathrm{O}$ Estado brasileiro não possui política ou programa de saúde mental direcionado especificamente para crianças com problemas de comportamento ou com transtornos externalizantes. Contudo, o tema aparece 
transversalmente nos estudos que se referem à saúde mental infantil, dada a alta prevalência de diagnósticos relacionados a comportamentos externalizantes na rede de atenção, conforme descrito nos estudos epidemiológicos nacionais (GARCIA, SANTOS; MACHADO, 2015; SANTOS et al, 2016). Os estudos acerca da temática nesse eixo se concentram no ramo do planejamento e gestão em saúde, com pesquisas sobre o estabelecimento de conjuntos coordenados de açôes, que incluem estratégias, planejamento e avaliação de políticas, programas e tecnologias de saúde, a gestão de sistemas, serviços, recursos humanos, qualidade etc. Os estudos selecionados da PPGS foram três qualitativos dos tipos hermenêutico, de significação e descritivo; um qualitativo-quantitativo do tipo avaliativo educacional; e um quantitativo do tipo avaliativo transversal; todos nacionais, conforme expóem os resumos no seguinte Quadro 3.

Quadro 3. Resumo dos estudos da política, planejamento e gestão em saúde acerca da criança com comportamentos externalizantes.

\begin{tabular}{|c|c|c|}
\hline Estudo & Metodologia & Resultados/Considerações \\
\hline $\begin{array}{l}\text { XI. Articulação entre } \\
\text { Serviços Públicos } \\
\text { de Saúde nos } \\
\text { Cuidados Voltados } \\
\text { à Saúde Mental } \\
\text { Infantojuvenil } \\
\text { (DELFINI; REIS, } \\
\text { 2012). }\end{array}$ & $\begin{array}{l}\text { Tipo: Hermenêutico, referenciado } \\
\text { em Habermas (qualitat.) - busca a } \\
\text { compreensáo interpretativa de um } \\
\text { tema ou objeto a partir da confluência } \\
\text { dialética entre pesquisador e sujeito/ } \\
\text { objeto pesquisado. } \\
\text { Âmbito/Local: Nacional, município } \\
\text { de São Paulo, estado de São Paulo. } \\
\text { Sujeitos/objeto: Gerentes de unidades } \\
\text { da Estratégia Saúde da Família (ESF) } \\
\text { e CAPSi pesquisados sobre os modos } \\
\text { de articulação entre suas equipes de } \\
\text { trabalhadores. } \\
\text { Técnicas/Instrumentos: Entrevistas } \\
\text { semiestruturadas com dados } \\
\text { interpretados a partir de análise de } \\
\text { conteúdo. }\end{array}$ & $\begin{array}{l}\text { A escassez de recursos humanos, a } \\
\text { cobrança por produtividade e a ausência } \\
\text { de capacitação dos profissionais da } \\
\text { ESF para trabalhar com a saúde mental } \\
\text { são obstáculos para uma articulação } \\
\text { efetiva entre os serviços; as práticas } \\
\text { em destaque na articulaçáo entre as } \\
\text { equipes da ESF e do CAPSi são o } \\
\text { encaminhamento de casos, o apoio } \\
\text { matricial e a parceria para casos } \\
\text { considerados pertinentes, porém com } \\
\text { características de desresponsabilização, } \\
\text { prevalência do discurso biomédico e } \\
\text { fragmentação dos cuidados. Enfatiza os } \\
\text { problemas comuns nos dois serviços e } \\
\text { indica a necessidades de mudanças. }\end{array}$ \\
\hline
\end{tabular}




\begin{tabular}{|c|c|c|}
\hline Estudo & Metodologia & Resultados/Consideraçóes \\
\hline $\begin{array}{l}\text { XII. Saúde Mental } \\
\text { Infantil na Atenção } \\
\text { Primária à Saúde: } \\
\text { discursos de } \\
\text { profissionais médicos } \\
\text { (GOMES et al, } \\
\text { 2015). }\end{array}$ & $\begin{array}{l}\text { Tipo: De significação referenciado na } \\
\text { Psicologia Sócio-Histórica (qualitat.) } \\
\text { - busca apreender e interpretar os } \\
\text { sentidos e significados sobre um tema } \\
\text { como produto de atos de pensamento. } \\
\text { Âmbito/Local: Nacional, município } \\
\text { de Divinópolis, estado de Minas } \\
\text { Gerais. } \\
\text { Sujeitos/Objeto: Médicos da } \\
\text { Atenção Primária vinculados à ESF } \\
\text { e pediatras de Unidades Básicas não } \\
\text { vinculados à ESF, pesquisados sobre } \\
\text { sentidos e significados produzidos } \\
\text { acerca da saúde mental infantil. } \\
\text { Técnicas/Instrumentos: Entrevistas } \\
\text { semiestruturadas analisadas a partir } \\
\text { de núcleos de significação. }\end{array}$ & $\begin{array}{l}\text { Núcleos de significação: (1) há limitado } \\
\text { comprometimento com o cuidado das } \\
\text { condiçóes inerentes à saúde mental } \\
\text { infantil; (2) a "família desestruturada" } \\
\text { seria a principal determinante de } \\
\text { psicopatologias da criança; (3) a } \\
\text { responsabilidade pela saúde mental } \\
\text { da criança é atribuída sobretudo à } \\
\text { mãe; (4) o parecer do "especialista" } \\
\text { e a prescriçáo de medicamento são } \\
\text { os atos mais esperados em relação } \\
\text { às demandas psicopatológicas da } \\
\text { criança; (5) há fragmentação das ações } \\
\text { de cuidado e responsabilidades no } \\
\text { tratamento da criança, com a lógica de } \\
\text { encaminhamentos. Aponta o cuidado } \\
\text { integral como direito da criança; a } \\
\text { importância da escuta dos cuidadores } \\
\text { e da concentração de esforços para } \\
\text { açốes intersetoriais e formação dos } \\
\text { profissionais. }\end{array}$ \\
\hline
\end{tabular}

XIII. Avaliação

do Atributo

Integralidade na

Atenção à Saúde da

Criança (DINIZA et al, 2016).

\section{Tipo: Avaliativo transversal}

(quantitat.) - busca medir um ou mais aspectos específicos, os quais se espera observar em um dado contexto.

Âmbito/Local: Nacional, município de João Pessoa, estado da Paraíba.

Sujeitos/Objeto: Pais/cuidadores de crianças atendidas na Atenção Primária com ESF, pesquisados sobre o atributo integralidade, que inclui a saúde mental.

Técnicas/Instrumentos: Aplicação do instrumento Primary Care Assessment Tool (Instrumento de Avaliação da Atenção Primária) PCATool-Brasil, analisado com ênfase no atributo integralidade.
$\mathrm{O}$ atributo integralidade, que se refere a açôes conjugadas direcionadas à materialização da saúde, de modo a refletir nas ações profissionais diante das peculiaridades do usuário, não obteve escores satisfatórios nas dimensōes de serviços disponíveis e serviços prestados. O resultado representa extensão fora da meta para um serviço de Atenção Primária à Saúde. Sugere a necessidade de reestruturação dos serviços, com a busca de articulaçôes intersetoriais na oferta da atenção à saúde da criança e a valorização das relações entre profissionais e usuários a fim de promover uma dimensão cuidadora efetiva e integral. 


\begin{tabular}{|c|c|c|}
\hline Estudo & Metodologia & Resultados/Consideraçóes \\
\hline $\begin{array}{l}\text { XIV. Estratégia } \\
\text { Educacional em } \\
\text { Saúde Mental para } \\
\text { Médicos da Atenção } \\
\text { Básica (PEREIRA; } \\
\text { ANDRADE, 2018). }\end{array}$ & $\begin{array}{l}\text { Tipo: Avaliativo Educacional } \\
\text { (qualitat./quantitat.) - busca traçar } \\
\text { um conjunto de aspectos qualitativos } \\
\text { e/ou quantitativos referentes a } \\
\text { determinado tema ou objeto } \\
\text { educacional. } \\
\text { Âmbito/Local: Nacional, município } \\
\text { de Sobral, estado do Ceará. } \\
\text { Sujeitos/Objeto: Médicos } \\
\text { trabalhadores em Unidades Básicas } \\
\text { de Saúde e docentes de Escolas de } \\
\text { Medicina pesquisados acerca da } \\
\text { estratégia educacional em saúde } \\
\text { mental para médicos da Atenção } \\
\text { Básica. } \\
\text { Técnicas/Instrumentos: Revisão } \\
\text { narrativa de literatura, aplicação de } \\
\text { questionários e grupos focais, com } \\
\text { dados interpretados via Epi InfoTM } \\
\text { - programa estatístico (quantit.) e } \\
\text { análise de conteúdo (qualit.). }\end{array}$ & $\begin{array}{l}\text { Os problemas de comportamento } \\
\text { na infância e adolescência são tema } \\
\text { prioritário para } 53 \% \text { dos médicos e } \\
\text { constam no programa do curso da } \\
\text { proposta educativa produzida no } \\
\text { estudo, com objetivos de: diagnóstico } \\
\text { precoce; promoção, prevenção e } \\
\text { reabilitaçáo psicossocial; prescrição } \\
\text { de tratamento psicofarmacológico } \\
\text { ou não; encaminhamento para } \\
\text { técnicos da equipe e/ou para serviços } \\
\text { especializados. Alguns problemas } \\
\text { apontados na Atenção Básica são a falta } \\
\text { de protocolos, dificuldades no trabalho } \\
\text { em comunidade e no engajamento dos } \\
\text { familiares de pacientes. Os docentes } \\
\text { apontaram a baixa qualidade do ensino } \\
\text { de saúde mental na formação geral } \\
\text { médica. Propóe que os trabalhadores } \\
\text { médicos da atenção básica participem } \\
\text { da formulaçáo de planos educacionais } \\
\text { em saúde mental. }\end{array}$ \\
\hline $\begin{array}{l}\text { XV. A Pesquisa } \\
\text { em Prevençáo em } \\
\text { Saúde Mental no } \\
\text { Brasil: A perspectiva } \\
\text { de especialistas } \\
\text { (ABREU; MURTA, } \\
\text { 2018). }\end{array}$ & $\begin{array}{l}\text { Tipo: Descritivo (qualitat.) - busca } \\
\text { traçar um conjunto de características } \\
\text { e aspectos qualitativos referentes a } \\
\text { determinado tema ou objeto. } \\
\text { Âmbito/Local: Nacional, Brasil. } \\
\text { Sujeitos/Objeto: Pesquisadores/ } \\
\text { especialistas pesquisados sobre a } \\
\text { produção de conhecimento acerca da } \\
\text { Prevenção em Saúde Mental. } \\
\text { Técnicas/Instrumentos: Revisão } \\
\text { narrativa de literatura e consultas aos } \\
\text { pesquisadores/especialistas a partir } \\
\text { da técnica Delphi, com contatos } \\
\text { via internet e aplicação remota de } \\
\text { instrumentos de autorrelato. }\end{array}$ & $\begin{array}{l}\text { Indica produção reduzida, mas crescente, } \\
\text { sobre programas de promoção da saúde } \\
\text { mental e desenvolvimento positivo } \\
\text { para crianças. Indica que a produção } \\
\text { de conhecimento sobre prevenção em } \\
\text { saúde mental pode ser beneficiado } \\
\text { por: a)desenvolvimento de múltiplas } \\
\text { competências teóricas e metodológicas; } \\
\text { b)interlocuçấo entre campos de } \\
\text { conhecimento; c) maior aproximação } \\
\text { entre ensino, pesquisa e extensão, desde } \\
\text { a graduação; d)diálogo da academia com } \\
\text { poderes públicos para formulação de } \\
\text { políticas em saúde mental. Sugere novos } \\
\text { estudos que incluam gestores, formadores } \\
\text { e trabalhadores de linha de frente na } \\
\text { prevenção em saúde mental. Ressalta } \\
\text { a importância de constituir planos de } \\
\text { ação para enriquecer a produção de } \\
\text { conhecimento sobre o tema. }\end{array}$ \\
\hline
\end{tabular}


Os estudos na área da PPGS tangenciam a problemática da criança com comportamentos externalizantes ao avaliar de modo geral ou em recortes a política de saúde mental para a infância e adolescência no Brasil. A representação dos trabalhos aqui tratados busca dar conta do estado de desenvolvimento e consolidação de programas e estratégias em saúde mental para o público infanto-juvenil no Brasil. Tais estudos têm sido voltados principalmente para os serviços do CAPSi e da Atençáo Primária, com ênfase sobre a qualidade, os recursos humanos, a formação continuada, a intersetorialidade e a integralidade. Nesse sentido, é possível perceber algum esforço de aproximação dialógica com a epidemiologia e com as ciências sociais em saúde, na medida em que trata de respostas em políticas públicas dadas a demandas apresentadas por aqueles outros dois eixos disciplinares da Saúde Coletiva. Entretanto, não se encontram facilmente nos estudos da PPGS referências nítidas à epidemiologia e às ciências sociais em saúde, de modo a explicitar um diálogo interdisciplinar, seja com a confrontação de dados, seja com a indicação da necessidade de novos estudos.

Em termos de consideraçóes, os estudos da PPGS apontam para a necessidade de investimentos públicos na expansão da rede de atenção à saúde mental para a infância e adolescência, na efetivação de ações intersetoriais e na formação continuada de profissionais, tanto da atenção primária como da atenção psicossocial. Ademais, sugerem ainda uma formação profissional atenta à melhoria da comunicação intersetorial e comunitária, com usuários e familiares em suas necessidades singulares, bem como à quebra de hegemonia do discurso biomédico, com vistas à integralidade e à superação da lógica dos encaminhamentos.

Os modos de considerar a criança nas pesquisas acerca da saúde mental para a infância e adolescência na PPGS têm trazido o componente do silenciamento infantil, de modo semelhante aos demais eixos disciplinares. Em se tratando de uma área específica relacionada a políticas públicas, é algo a se chamar especialmente a atenção, considerando os diversos estudos das ciências sociais e humanas, desde pelo menos a década de 1990, acerca dos "direitos participaçáa” de crianças e adolescentes (SARMENTO, 2018; SARMENTO; PINTO, 1997; MONTANDON, 2001; SIROTA, 2001; KOHAN, 2008; PROUT, 2010; VALENÇA, 2017).

\section{Consideraçóes Finais}

Cumprindo o objetivo proposto, esta revisão de literatura termina por apresentar, de modo narrativo, um panorama empírico de estudos acerca da saúde 
mental da criança com problemas de comportamento. Pensando numa relação não dicotômica-opositora entre as ciências naturais e as ciências sociais e humanas, e entre o simples e o complexo, buscou-se sinalizar lacunas e controvérsias nos estudos aqui analisados, desenvolvidos no campo da Saúde Coletiva, o qual se pretende ao menos interdisciplinar, senão transdisciplinar (ALMEIDA-FILHO, 2005; ROQUETE et al, 2012).

Os estudos epidemiológicos analisados, de importância inequívoca acerca da distribuição dos problemas e dos fatores de risco relativos à criança com comportamentos externalizantes, aparecem marcados por: 1) ausência de referência a estudos das ciências sociais em saúde ou, ao menos, de sinalização sobre a importância de problematizar qualitativamente as realidades descritas e, especialmente, os determinantes sociais verificados para os problemas de comportamento na infância; 2) falta de sinalização das diversas possibilidades de mediação das informaçôes epidemiológicas produzidas acerca do tema, o que pode indicar, implicitamente, um viés para a mediação biomédica.

A análise dos estudos nas ciências sociais em saúde, muitos de fundamental importância política no enfrentamento ao poder hegemônico do discurso biomédico em saúde mental, aponta principalmente: 1) uma maciça polarização discursiva em relação às ciências médicas e farmacêuticas; 2) a ausência de objetivos voltados a compreender os modos de constituição social dos comportamentos considerados inadequados para crianças, em diálogo com a epidemiologia descritiva.

A literatura em análise do eixo PPGS, que tangencia a problemática da criança com problemas de comportamentos em avaliaçôes da política de saúde mental para a infância e adolescência no Brasil, teve como principais características observadas: 1) a aproximação dialógica precária com os demais eixos disciplinares, com falta de referências nítidas e capazes de explicitar um diálogo interdisciplinar com a epidemiologia e as ciências sociais em saúde; 2) articulação insuficiente no sentido de sugerir o potencial de ampliar o foco do paradigma da intersetorialidade, visando alcançar a interdisciplinaridade efetiva ou a transdisciplinaridade.

O desencontro discursivo entre os eixos da epidemiologia e das ciências sociais em saúde sobre as crianças com problemas de comportamento dificilmente deixaria de gerar efeitos negativos sobre a formulação e a avaliação das políticas, programas e tecnologias voltadas para a saúde mental na infância e adolescência. Talvez seja essa a razão de não haver, por exemplo, uma política ou programa de saúde mental, 
formulado pelo Estado brasileiro, especificamente para crianças e adolescentes com problemas de comportamento ou com transtornos externalizantes. Com uma melhor integração entre os eixos disciplinares da Saúde Coletiva é provável que haja contribuiçôes mais férteis para a planificação, gestão e a avaliação de políticas, programas e tecnologias em saúde mental para a infância e adolescência, ou mesmo voltadas especificamente à problemática dos comportamentos externalizantes, com seus altos índices de prevalência e os controversos diagnósticos e terapêuticas (GARCIA; SANTOS; MACHADO, 2015; SANTOS et al, 2016; MURRAY et al, 2015; SANCHES; AMARANTE, 2015; DOMITROVIC; CALIMAN, 2017).

Ressalta-se, portanto, o valor de estudos que enfatizem a superação das oposiçóes dicotomizadas, tendo como ponto de partida a linguagem da complexidade, da multiplicidade, da instabilidade, do hibridismo, das redes e das mediaçóes do mundo social, no qual a ciência se insere como prática (LATOUR; WOOLGAR, 1988; D’AMBRÓSIO, 2001; MORIN, 2002; ALMEIDA-FILHO, 2005; PROUT, 2010; LATOUR, 2012). Logo, reforça-se a importância, para a Saúde Coletiva, de abordagens ampliadas sobre as múltiplas realidades referentes aos processos saúdedoença-cuidado, com efetivo diálogo entre áreas de conhecimento.

É salutar persistir em trazer à luz o pensamento complexo alinhado com ideia de uma pedagogia da transdisciplinaridade, com potência para superar hierarquizaçóes e fronteiras entre sistemas de explicação diversos, eliminar oposiçóes dicotomizadas e transcender o lugar das especialidades. Somente a partir de um esforço coletivo e cooperativo, baseado em uma ética livre de vaidades, arrogâncias e prepotências, será possível vislumbrar para além de uma "utopia", no fértil campo da Saúde Coletiva, uma transdisciplinaridade capaz de disjuntar e associar, de modo a conceber níveis de emergência das realidades sem reduzi-los a unidades elementares e a leis gerais (D’AMBRÓSIO, 2001; MORIN, 2002).

As noções de complexidade e transdisciplinaridade permitem aproximar e, quiçá, incluir as diversas epistemologias e metodologias, as chamadas ciências duras (ou naturais) e as ciências leves (ou sociais e humanas), os estudos quantitativos e os qualitativos, os estudos dos agregados sócio-históricos e os das práticas cotidianas etc. (D’AMBRÓSIO, 2001; MORIN, 2002; ALMEIDA-FILHO, 2005). Inúmeras vezes, seja nas ciências naturais ou nas ciências sociais e humanas, o paradigma da simplificação, com os princípios da generalidade (do particular para o geral), da redução (do todo para partes) e da abstração (do objeto empírico descolado de fatores 
relacionados) (D’AMBRÓSIO, 2001; MORIN, 2002; ALMEIDA-FILHO, 2005), se mostra útil a aspectos didáticos e à indicação/introdução de bases importantes para açôes ou para estudos mais complexos. A própria epistemologia da complexidade dificilmente teria emergido antes que o paradigma da simplificação da ciência moderna tivesse se consolidado e indicado, por seus produtos e aplicaçóes, que se fazia necessária uma nova atitude intelectual diante de múltiplos entendimentos para realidades cada vez mais complexas (D’AMBRÓSIO, 2001; MORIN, 2002; ALMEIDA-FILHO, 2005).

No entanto, com essas colocaçóes, não se pretende declinar aqui para uma defesa do perspectivismo. De acordo com a linguagem da complexidade e da multiplicidade que se busca aplicar na totalidade deste estudo, é possível entender as práticas científicas como relaçóes entre actantes humanos e não humanos, que atuam e são atuados nas redes, constituindo versôes de realidades com as mediaçôes do mundo social (LATOUR; WOOLGAR, 1988; PROUT, 2010; LATOUR, 2012). Ou seja, as práticas científicas se dão no encontro de humanospesquisadores com humanos-pesquisados e/ou com não-humanos-pesquisados, referenciais e instrumentos de pesquisa, todos actantes (pessoas, elementos da natureza, arranjos geográficos, registros, máquinas, ideias, discursos, dispositivos, instituiçóes etc.), sempre dotados de historicidade e de saberes implícitos ou explícitos (LATOUR; WOOLGAR, 1988; D’AMBRÓSIO, 2001; MORIN, 2002; ALMEIDA-FILHO, 2005; LATOUR, 2010).

Retornando ao panorama apresentado neste estudo, o silenciamento infantil incorre como uma constante na literatura revisada dos três eixos disciplinares fundamentais da Saúde Coletiva acerca da criança com comportamentos externalizantes. Assim sendo, tal resultado faz reavivar a ideia de que, para além da abertura de fronteiras entre as áreas de conhecimento, transcendendo especialidades, o paradigma da transdisciplinaridade também implica considerar os sujeitos-objetos da pesquisa, com a valorização dos seus saberes, práticas e vivências, como atores centrais do conhecimento sobre si (D’AMBRÓSIO, 2001; MORIN, 2002; ALMEIDA-FILHO, 2005; LATOUR, 2010). Ou seja, a criança deve ser reconhecida como ator central nas pesquisas sobre temas que lhe digam respeito, como os seus comportamentos considerados problemáticos, com atenção a tudo o que possa mediar os conflitos que só se produzem nas relaçôes. Para além de uma pedagogia, a transdisciplinaridade precisa ser alcançada como uma práxis cotidiana em processos coletivos e cooperativos 
de produção de conhecimento, de modo a garantir participação efetiva das crianças e de outros grupos inferiorizados nessas dinâmicas.

Nesse sentido, a superação das práticas de silenciamento infantil nas pesquisas científicas não pode se restringir à mera inclusão das crianças em procedimentos de entrevista, aplicação de testes e questionários ou observaçóes dialogadas. $\mathrm{O}$ silenciamento persiste se a expressáo da criança continua submetida a crivos de pretensas hierarquias e especialidades que buscam o "porquê", ou as causas das diferenças e desvios da normalidade, e afastam o "como", ou os processos que constituem as diferenças, algo que só pode ser substancialmente acessado através da compreensão dos saberes e práticas da criança consigo e com o mundo. Portanto, se faz necessário que a produção científica sobre a infância se dê em uma relação de intercâmbio horizontal e reflexivo do ator-pesquisador com os atores-pesquisados, dimensionando geraçóes, lugares de saber-fazer-dizer, territórios e culturas, sem (re) produzir atos colonizadores sob a suposta justificativa de domínio de uma área ou “especialidade” (GUIMARÃES, 2018).

Estudos futuros de revisão de literatura sobre essa temática podem abordar as práticas de silenciamento infantil e as barreiras ao pensamento complexo e transdisciplinar na relação com o discurso científico que embasa as normas de publicação dos periódicos em Saúde Coletiva, no sentido de analisar como a política editorial adotada tende a corroborar um modelo específico e hegemônico de produção científica, legitimando certas práticas e impedindo outras.

\section{Referências}

ABREU, S.; MURTA, S. G. A Pesquisa em Prevenção em Saúde Mental no Brasil: A perspectiva de especialistas. Psic Teor Pesq, v.34, e34413, 2018.

ACHENBACH, T. M. ASEBA - Achenbach System of Empirically Base Assessment [página da web] 2017. Disponível em: <http://www.aseba.org/dsm5.html>. Acesso em: 20/03/2018.

. The Classification of Children's Psychiatric Symptoms: a factor-analytic study. Psychological Monografhs: general and applied, v.80, n.7, p.1-37, 1966.

ACHENBACH, T. M.; ELDEBROCK, C. S. The Classification of Child Psychopathology: a review and analysis of empirical efforts. Psychol Bull, v.85, n.6, p.1275-1301, 1978.

ALMEIDA-FILHO, N. Transdisciplinaridade e o Paradigma Pós-Disciplinar na Saúde. Saude Soc, v.14, n.3, p.30-50, 2005. 
AMARANTE, P. Teoria e Crítica em Saúde Mental: textos selecionados. 2. ed. São Paulo: Editora Zagodoni, 2017.

ANGELUCCI, C. B.; SOUZA, B. P. (org.). Medicalização de Crianças e Adolescentes: conflitos silenciados pela redução de questóes sociais a doenças de individuos. 1a Ed. São Paulo: Casa do Psicólogo, 2010.

APA - American Psychiatric Association. Diagnostic and Statistical Manual of Mental Disorders. 4.ed. (DSM-IV). Fact Sheet, 1997.

. Manual Diagnóstico e Estatístico de Transtornos Mentais. 5.ed. (DSM-V). Tradução: Maria Inês Nascimento. Porto Alegre: Artmed, 2014.

ARIÈS, P. História Social da Criança e da Família. 2. ed. Tradução: Dora Plasmam. Rio de Janeiro: LTC Editora, 1981.

ASSIS, S. G.; AVANCI, J. Q.; OLIVEIRA, R. V. C. Desigualdades Socioeconômicas e Saúde Mental Infantil. Rev Saude Publica, v.43, sup.1, p.92-100, 2009.

BARROS, P.; SILVA, F. B. N. Origem e Manutenção do Comportamento Agressivo na Infância e Adolescência. Revista Brasileira de Terapia Comportamental e Cognitiva, v.2, n.1, p.55-66, 2006.

BRASileiro, A. M. M. Manual de Produção de Textos Acadêmicos e Científicos. São Paulo: Atlas, 2013.

BRZOZOWSKI, F. S.; CAPONI, S. Determinismo Biológico e as Neurociências no Caso do Transtorno de Déficit de Atenção com Hiperatividade. Physis, v.22, n.3 p.941-961, 2012.

CALEIRO, F. M.; SILVA, R. S. Técnica de Modificação de Comportamento de Crianças com Treinamento de Pais. Encontro: Revista de Psicologia, v.15, n.23, p.129-142, 2012.

CONRAD, P. The Medicalization of Society: on the transformation of human conditions in to treatable disorders. Baltimore: The John Hopkins University Press, 2007.

CONRAD, P.; BERGEY, M. The Impending Globalization of ADHD: notes on the expansion and growth of a medicalized disorder. Soc Sci Med, v.122, p.31-43, 2014.

D’ABREU, L. C. F. O Desafio do Diagnóstico Psiquiátrico na Criança. Contextos Clinicos, v.5, n.1, p.2-9, 2012.

D’AMBRÓSIO, U. Transdisciplinaridade. São Paulo: Palas Athena, 2001.

DELFINI, P. S. S.; REIS, A. O. A. Articulação entre Serviços Públicos de Saúde nos Cuidados Voltados à Saúde Mental Infanto-juvenil. Cad Saude Publica, v.28, n.2, p.357-366, 2012.

DINIZA, S. G. M.; DAMASCENO, S. S.; COUTINHO, S. E. D.; TOSO, B. R. G. O.; COLLET N. Avaliação do Atributo Integralidade na Atenção à Saúde da Criança. Rev Gaucha Enferm, v.37, n.4, p.1-8, 2016. 
DOMitroviC, N.; CALIMAN, L. V. As Controvérsias Sócio-Históricas das Práticas Farmacológicas com o Metilfenidato. Psicol Soc, v.11, p.1-12, 2017

DONZELOT, J. A Polícia das Famílias. 2. ed. Rio de Janeiro: Graal, 1986.

FOUCAULT, M. A Ordem do Discurso. São Paulo: Loyola, 1996.

FRANCES, A. Voltando ao Normal. Rio de Janeiro: Versal Editores, 2016.

GARCIA, G. Y. C; SANTOS, D. N.; MACHADO, D. B. Centros de Atenção Psicossocial Infantojuvenil no Brasil: Distribuição geográfica e perfil dos usuários. Cad Saude Publica, v.31, n.12, p.2649-2654, 2015.

GOMES, F. M. A.; CINTRA, A. M. O.; RICAS, J..; VECCHIA, M. D. Saúde Mental Infantil na Atenção Primária à Saúde: discursos de profissionais médicos. Saude Soc, v.24, n.1, p.244-258, 2015.

GUIMARĀES, A. L. P. Fios que Urdem Tecituras: práticas e sentidos constituindo versóes da criança com comportamentos externalizantes. Dissertação (Mestrado Acadêmico em Saúde Comunitária) - Instituto de Saúde Coletiva - UFBA, Salvador, 2018.

KLEINMAN, A.; KLEINMAN, J. Suffering and its Professional Transformation: Toward an ethnography of interpersonal experience. Cult Med Psychiatry, v.15, n.3, p.275-301, 1991.

KOHAN, W. O. Infância e Filosofia. In: SARMENTO, M. J.; GOUVEA, M. C. S.(orgs.). Estudos da Infância: educação e práticas sociais. Rio de Janeiro: Vozes, 2008. p.40-61.

LANDMAN, P. Tous hyperactifs? L'incroyable épidémie de troubles de l'attention. Paris: Éditions Albin Michel, 2015.

LATOUR, B. Reagregando o Social: uma introdução à Teoria Ator-Rede. Salvador: EDUFBA/ Edusc, 2012.

LATOUR, B; WOOLGAR, S. A Vida de Laboratório: a produção dos fatos científicos. Tradução: Ângela R. Vianna. Rio de Janeiro: Relume Dumará, 1988.

LIMA, R. C. Três Tópicos sobre a Relação entre DSM e Política. In: KYRILLOS-NETO, F. CALAZANS, R. (orgs.). Psicopatologia em Debate: controvérsias sobre os DSMs. Barbacena: EdUEMG, 2012, p.95-111.

LORENZI, C. G.; RISSATO, G. B.; SILVA, S. P. Sentidos Construídos por Educadores sobre Transtorno do Déficit de Atenção e Hiperatividade e Implicaçóes para a Prática Educativa. Saude Transform Soc, v.3, n.2, p.84-95, 2012.

MONTANDON, C. Sociologia da Infância: Balanço dos trabalhos em língua inglesa. Cad Pesqui, v.112, p.33-60, 2001.

MORIN, E. Educação e complexidade: Os setes saberes e outros ensaios. São Paulo: Cortez, 2002. 
MURRAY, J.; MENEZES, A. M. B.; HICKMAN, M.; MAUGHAN, B.; GALLO, E. A. G.; MATIJASEVICH, A.; GONÇALVES, H.; ANSELMI, L.; ASSUNÇÃO, M. C. F.; BARROS, F. C.; VICTORA, C. G. Childhood behaviour problems predict crime and violence in late adolescence: Brazilian and British birth cohort studies. Soc Psychiatry Epidemiol, v.50, p.579-589, 2015.

NAKAMURA, E.; BARBARINI, T. Comportamentos infantis problemáticos, perturbadores e não conformes: Conceitos e demandas de cuidado relacionados à agitação em crianças em Santos e Campinas, Brasil. Saude Soc, v.28, n. 1, p.12-26, 2019.

NGOUNDO-MBONGUE, T. B.; SOMMET, A.; PATHAK, A.; MONTASTRUC, J. L. "Medicamentation" of Society, Non-diseases and Non-medications: A point of view from social pharmacology. Eur J Clin Pharmacol, v. 61, n. 43, p. 309-313, 2005.

OMS - Organização Mundial da Saúde; CBCD - Centro Brasileiro de Classificação de Doenças. Classificação Estatística Internacional de Doenças e Problemas Relacionados à Saúde. 10. ed. (CID10). São Paulo: EdUSP, 2008.

PAIM, J. S. ALMEIDA-FILHO, N., (org.). Saúde Coletiva: teoria e prática. Rio de Janeiro: MedBook, 2014.

PAIM, J. S.; TEIXEIRA, C. F. Política, Planejamento e Gestão em Saúde: balanço do estado da arte. Rev Saude Publica, v.40, n.esp., p.73-78, 2006.

PEREIRA, A. A.; ANDRADE, D. C. L. Estratégia Educacional em Saúde Mental para Médicos da Atenção Básica. Rev Bras Educ Med, v.42, n.1, p.4-12, 2018.

PLAISANCE, E. Denominaçóes da Infância: do anormal ao deficiente. Educ Soci, v. 26, p. 405-417, 2005.

POTON, W. L.; SOARES, A. L. G.; MENEZES, A. M. B.; WEHRMEISTER, F. C.; GONÇALVES, H. Amamentação e comportamentos externalizantes na infância e adolescência em uma coorte de nascimentos. Rev Bras Psiquiatr, v.41, e142, 2017.

PROUT, A. Reconsiderando a Nova Sociologia da Infância. Tradução: Fátima Murad. Cad Pesqui, v.40, n.141, p.729-750, 2010.

ROQUETE, F. F.; AMORIM, M. M. A.; BARBOSA, S. P.; SOUZA, D. C. M.; CARVALHO, D. V. Multidisciplinaridade, Interdisciplinaridade e Transdisciplinaridade: Em busca de diálogo entre saberes no campo da Saúde Coletiva. R Enferm Cent O Min, v.2, n.3, p.463-474, 2012.

ROTHER, E. T. Revisão Sistemática X Revisão Narrativa. Acta Paul Enferm, v.20, n.2, p.v-vi, 2007.

ROUQUAYROL, M. Z.; ALMEIDA-FILHO, N. Epidemiologia \& Saúde, 6o edição, Rio de Janeiro: Ed. MEDSI, 2003. 
SANCHES, V. N. L.; AMARANTE, P. D. C. Estudo sobre o Processo de Medicalização de Crianças no Campo da Saúde Mental. Saude Debate, v.38, n.102, p.506-514, 2014.

SANTOS, L. M.; QUEIRÓS, F. C.; BARRETO, M. L., SANTOS, D. N. Prevalence of Behavior Problems and Associated Factors in Preschool Children from the City of Salvador, State of Bahia, Brazil. Rev Bras Psiquiatr, v.38, n.1, p.46-52, 2016.

SARMENTO, M. J. A Sociologia da Infância portuguesa e o seu contributo para o campo dos estudos sociais da infância. Contemporânea, v. 8, n. 2, p. 385-405, 2018.

. Geraçôes e Alteridade: Interrogações a partir da sociologia da infância. Educ Soci, v.26, n.91, p.361-378, 2005.

SARMENTO, M. J.; PINTO, M. As Crianças e a Infância: Definindo conceitos, delimitando o campo. In: SARMENTO, M. J.; PINTO, M. (orgs.). As Crianças: contexto e identidades. Braga, Portugal: Universidade do Minho, Centro de Estudos da Criança, 1997.

SIQUEIRA, C. M.; GURGEL-GIANERTTI, J. Mau Desempenho Escolar: uma visão atual. Rev Ass Med Bras, v.57, n.1, p.78-87, 2011.

SIROTA, R. Emergência de uma Sociologia da Infância: evolução do objeto e do olhar. Cad Pesqui, v.112, p.07-31, 2001.

SOUZA, B. P. (org.). Orientação à Queixa Escolar. São Paulo: Casa do Psicólogo, 2007.

STOLKINER, A. Infancia y Medicalización en la Era de la Salud Perfecta. Propuesta Educativa, v.37, n.1, p.28-38, 2012.

VALENÇA, V. L. C. A participação das crianças no cotidiano: da progressão individual às reproduçôes coletivas. Educação Unisinos, v.21, n.1, p.3-11, 2017.

VINOCUR, E.; PEREIRA, H. V. F. S. Avaliação de Transtornos de Comportamento na Infância. Rev Hosp Univ Pedro Ernesto, v.10, n.2, p.26-34, 2011. 


\section{Abstract}

\section{The Public Health and the Child \\ Externalizing Behavior: a revision of literature}

The externalizing behaviors refer to a set of impulsive reactions that exteriorized by children (or adolescents) produce conflicts and, in a repetitive and persistent pattern, are associated with psychopathological syndromes and disorders. This article has the objective of empirical review on the subject, in three disciplinary axes of Public Health. It follows the systematic review method, with an empirical focus and narrative format, taking science as social practice and raising qualitative aspects of literature produced between 2009 and 2019. The knowledge produced brings important cuts on the subject, however, the panorama reached reveals a discursive distance between the axes of epidemiology and of the social science, precariously approximated in the axis of health planning. The ways of considering the child in the research are with child silencing, prioritizing adults' perceptions about children. We come to considerations about the importance of effective interdisciplinarity and a pedagogy of transdisciplinarity capable of transcending the place of specialties and of recognizing the child, with the appreciation of his practices and knowledge, as the central actor of knowledge about himself.

Keywords: mental health; child behavior; epidemiology; social sciences; health policy. 